\title{
Adolescent alcohol use in rural South African high schools
}

\author{
H Onya', A Tessera², B Myers³ ${ }^{3}$ A Flisher ${ }^{4,5 \dagger}$ \\ ${ }^{1}$ Health Promotion Unit, School of Health Sciences, University of Limpopo Turfloop Campus, South Africa \\ 2Department of Statistics and Operations Research, University of Limpopo Turfloop Campus, South Africa \\ ${ }^{3}$ Alcohol and Drug Abuse Research Unit, South African Medical Research Council, South Africa \\ 4Division of Child and Adolescent Psychiatry and Adolescent Health Research Institute, University of Cape Town, South Africa \\ 5Research Centre for Health Promotion, University of Bergen Norway
}

tWe dedicate this paper to our co-author, colleague and friend, Professor John Alan Flisher, who passed away on 18th April 2010, in honor of his outstanding research on adolescent health in Africa

\begin{abstract}
Objective: To examine psychosocial correlates of lifetime alcohol use among adolescents in rural South African high schools. Method: Questionnaires were administered to 1600 students from 20 randomly selected high schools in the Mankweng district within Limpopo province. Self-report data on alcohol use, demographic, environmental and psychosocial variables were collected. Results: About $22 \%$ of the students had ever used alcohol. Males were 2.4 times more likely to use alcohol than females. For students who attended religious services, the odds of ever having used alcohol were double those of students who did not attend religious services. The fitted logistic regression model shows that gender, age, ever having smoked a cigarette, ever damaged property, walking home alone at night, easy availability of alcohol, thinking alcohol use was wrong, attending religious services and number of friends who used alcohol are the best predictors of alcohol use among high school students in this setting. Conclusion: The results underline the importance of addressing personal, family, peer and school conduct factors as part of alcohol education initiatives. Efforts to prevent alcohol use among rural high school students should focus on changing drinking behaviour and on reducing risk factors for problem drinking.
\end{abstract}

Keywords: Adolescents; Alcohol use; Rural High Schools; South Africa

Received: 21-04-2011

Accepted: $23-08-2011$

doi: http://dx.doi.org/10.4314/ajpsy.v15i5.44

\section{Introduction}

In South Africa, national and regional statistics on alcohol use indicate that most high school students have tried alcohol, many of them drinking at regular intervals. ${ }^{1-3}$ Studies have reported prevalence rates for current alcohol use ranging between 22\% and $26 \%$. Similarly, rates of heavy episodic or binge drinking are estimated to range from $14 \%$ to $40 \% \cdot{ }^{1-7}$ These patterns of alcohol use among South African adolescents is cause for concern as the early initiation of alcohol use is associated with a range of negative consequences including school drop-out, unprotected sexual behaviour that places the adolescent at risk for infectious disease and unwanted pregnancies, and the later development of alcohol use and other mental disorders. ${ }^{3-8}$

To intervene effectively and prevent alcohol-related consequences among adolescents, risk factors for the early onset of alcohol use must be identified. Previous South African

Correspondence

Dr HE Onya

Health Promotion Unit, School of Health Sciences University of Limpopo,

Private Bag X1106, Sovenga, 0727, South Africa

email: hans.onya@ul.ac.za or ho7@mweb.co.za studies identified several intrapersonal, interpersonal and environmental risk factors for adolescent alcohol use. Intrapersonal risks include age, grade level, gender, race, selfesteem, and psychological problems. ${ }^{3-5,8}$ At the interpersonal level, association with alcohol-using peers, family conflict, punitive parenting styles, and parental education, marital status and parental substance use have been associated with early

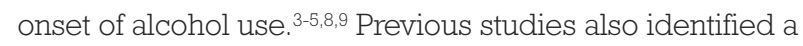
number of environmental risks for early alcohol use including boredom and a lack of healthy recreational activities, social norms that are supportive of alcohol use, and the widespread availability of alcohol in South African communities. ${ }^{8-11}$ However, as most of these earlier studies were conducted in urban settings, the extent to which these findings are relevant for adolescents from more rural communities is not known. This paper begins to redress this gap through examining risk factors for alcohol use among adolescents in one rural region of South Africa.

The rural Mankweng District in Limpopo Province was chosen as several studies have examined the prevalence of alcohol use among adolescents (see for example ${ }^{12-15}$ ) and documented alarming shifts in the pattern of alcohol 
consumption among adolescents from this district. Historically in this region, adolescent alcohol use was highly regulated, with adolescents only allowed to consume alcohol on traditional religious occasions. ${ }^{14}$ Changes in these drinking patterns have been noted, with adolescent alcohol use extending beyond these traditional boundaries and the frequency and quantity of alcohol consumption increasing in recent years. ${ }^{15}$ These shifts in patterns of alcohol use highlight the need to identify risk factors for adolescent alcohol use in this region that can be used to develop evidence-driven alcohol prevention programmes. This study begins to address this need though examining the correlates of alcohol use among high school students in the rural Mankweng district located within Limpopo province.

\section{Method \\ Study setting}

The study was conducted in Mankweng about 30 kilometres east of Polokwane, the provincial capital city of Limpopo Province in South Africa. The province has a population of 5.4 million people. Of these, $97.1 \%$ are black, $2.7 \%$ are white, and $0.1 \%$ coloured and Indian/Asian respectively; $45.7 \%$ of them are male; and $16.1 \%$ are teenagers. ${ }^{16}$ During the apartheid years all South Africans were classified in accordance with the Population Registration Act of 1950 into "racial groups" viz: "Black/African" (people mainly of African descent, "Coloured" (people of mixed descent), "Whites" (people mainly of European descent) or "Indian" (people mainly of Indian descent). The provision of services occurred along these "racially" segregated lines. The disproportionate provision of services to different "racial groups" led to inequalities. Information is still collected along these "racial" divisions in order to redress these inequalities. In no way do the authors subscribe to this classification.

Mankweng is a rural region, characterised mainly by periurban townships, tribal villages and informal settlements. Large families live in deprived conditions in this region, lacking satisfactory water supply, sanitation and access to basic services. ${ }^{17}$ Subsistence farming is common among people and a significant percentage of the labour force is unemployed. This pushes people to leave their families to seek employment elsewhere, which has profound implications as many young people have to take on parental responsibilities. Further, educational attainment in Limpopo Province is below the national level and the illiteracy rate is approximately 10\%. As one of the poorest provinces, Limpopo spends less on health services, including health promotion activities, than other provinces. ${ }^{16-18}$

\section{Participants}

The study population comprised all students attending high schools in Mankweng District in Limpopo Province, South Africa. At the time of the study, there were 63 high schools in Mankweng District, all of which were public schools. Twenty schools were randomly selected from the 63 schools for the study, such that the probability of a school being selected was directly proportional to the number of students in the school. For each school, 40 students were randomly selected from grade nine and 40 students were randomly selected from grade eleven. According to the school records, only 25 (1.5\%) of the students enrolled in the sampled schools absented themselves from school on the day of the research without any genuine reason or permission. The final study sample comprised 1600 students.

\section{Survey Questionnaire}

The questionnaire used in this study has been used with success by previous surveys of adolescent substance use in urban settings. ${ }^{5}$ The questionnaire had three parts. Part 1 included 15 items on the demographic and socioeconomic background of the student. Part 2 comprised 26 items relating to substance use and psychosocial correlates for substance use. To limit social desirability, students were asked if they had used a fictitious substance (Derbisol), and the eight students that responded positively to this item were excluded from further analyses. Part 3 consisted of 43 items that explored the use of home-brewed alcohol and various health-related risk behaviours. For this paper, we report only on alcohol use and the various variables thought to be correlated with alcohol use. Bilingual speakers translated the questionnaire into Northern Sotho/Pedi (the local language) and back translated the Northern Sotho version into English. In addition, the appropriateness of the questions for rural South African adolescents and young adults was established through focus group discussion with similar aged students at a randomly selected school within the same province.

\section{Data collection procedure}

The survey was administered during a normal class period by two research assistants. The research assistants, both of whom are Northern Sotho speakers, administered the survey questionnaire under conditions approximating examinations. To preserve the privacy of the students, the teachers were not present during the administration of the questionnaires. Anonymity and confidentiality were emphasised. Permission for the students to take part in the study was granted by the Department of Education and Culture of Limpopo Province. The study was approved by the Ethics Committee of the University of Limpopo and the University of Cape Town. Students who participated in the study were given a set of coloured pencils each to compensate for their time and cooperation.

\section{Data analysis}

Thirty three variables were first selected as possible correlates of alcohol use. The students were then cross classified by the use of alcohol (Yes/No) and each of the predictor variables. Tests of association were conducted to see if there were significant associations between these predictors and alcohol use. Based on these results, 23 variables were used as predictor variables and prevalence rates of alcohol use were estimated for the categories of these predictor variables. Next, logistic regression models for a complex sample were fitted with alcohol use as the response variable and the subsets of the predictor variables as explanatory variables. A logistic regression model with nine predictor variables was finally selected as the best model.

\section{Results}

This study found an overall prevalence for lifetime use of alcohol of $22.4 \%$. Less than $10 \%$ of the students in our sample reported ever smoking a cigarette. Very few students in our sample reported damaging property or carrying a knife to school. However, the proportion of students who reported walking home alone at night or being bullied was quite large (25.5\% and $36.9 \%$, respectively) (Table I). About a quarter of the students reported alcohol or drug problem in their families and close to $30 \%$ of the sample reported that their siblings used alcohol. A little over a quarter of the participants attended religious 


\begin{tabular}{|c|c|c|c|c|c|}
\hline Question Item & Category & Weighted \% & $\begin{array}{l}\text { Prevalence Rate } \\
\text { by alcohol }\end{array}$ & Adjusted F & Sig. \\
\hline Ever used alcohol? & $\begin{array}{l}\text { Yes } \\
\text { No }\end{array}$ & $\begin{array}{l}22.4 \% \\
77.6 \%\end{array}$ & & & \\
\hline Gender & $\begin{array}{l}\text { Female } \\
\text { Male }\end{array}$ & $\begin{array}{l}53.5 \% \\
46.5 \%\end{array}$ & $\begin{array}{l}11.5 \% \\
37.6 \%\end{array}$ & 98.863 & 0.00 \\
\hline Ever smoked a whole cigarette? & $\begin{array}{l}\text { No } \\
\text { Yes }\end{array}$ & $\begin{array}{l}91.6 \% \\
8.4 \%\end{array}$ & $\begin{array}{l}18.1 \% \\
71.9 \%\end{array}$ & 200.460 & 0.00 \\
\hline Stolen anything in the past 12 months? & $\begin{array}{l}\text { No } \\
\text { Yes }\end{array}$ & $\begin{array}{l}88.4 \% \\
11.6 \%\end{array}$ & $\begin{array}{l}22.1 \% \\
37.0 \%\end{array}$ & 27.068 & 0.00 \\
\hline Damaged property in the past 12 months? & $\begin{array}{l}\text { No } \\
\text { Yes }\end{array}$ & $\begin{array}{l}97.1 \% \\
2.1 \%\end{array}$ & $\begin{array}{l}22.8 \% \\
60.5 \%\end{array}$ & 25.103 & 0.00 \\
\hline Carry knife to school in the past 12 months? & $\begin{array}{l}\text { No } \\
\text { Yes }\end{array}$ & $\begin{array}{l}97.9 \% \\
2.1 \%\end{array}$ & $\begin{array}{l}23.0 \% \\
77.2 \%\end{array}$ & 34.218 & 0.00 \\
\hline Walk home alone at night in the past 4 weeks? & $\begin{array}{l}\text { No } \\
\text { Yes }\end{array}$ & $\begin{array}{l}74.5 \% \\
25.5 \%\end{array}$ & $\begin{array}{l}16.7 \% \\
44.4 \%\end{array}$ & 61.194 & 0.00 \\
\hline Bullied somebody in the past 12 months? & $\begin{array}{l}\text { No } \\
\text { Yes }\end{array}$ & $\begin{array}{l}78.2 \% \\
21.8 \%\end{array}$ & $\begin{array}{l}20.8 \% \\
36.7 \%\end{array}$ & 38.132 & 0.00 \\
\hline Been bullied in the past 12 months? & $\begin{array}{l}\text { No } \\
\text { Yes }\end{array}$ & $\begin{array}{l}63.1 \% \\
36.9 \%\end{array}$ & $\begin{array}{l}20.2 \% \\
29.0 \%\end{array}$ & 9.876 & 0.01 \\
\hline Involved in physical fight in the past 12 months? & $\begin{array}{l}\text { No } \\
\text { Yes }\end{array}$ & $\begin{array}{l}87.2 \% \\
12.8 \%\end{array}$ & $\begin{array}{l}21.8 \% \\
36.7 \%\end{array}$ & 15.472 & 0.00 \\
\hline Think of killing yourself in the past year? & $\begin{array}{l}\text { No } \\
\text { Yes }\end{array}$ & $\begin{array}{l}95.5 \% \\
4.5 \%\end{array}$ & $\begin{array}{l}22.7 \% \\
49.7 \%\end{array}$ & 23.928 & 0.00 \\
\hline Adults feel alcohol use by youth is wrong? & $\begin{array}{l}\text { Wrong } \\
\text { Not wrong }\end{array}$ & $\begin{array}{l}84.4 \% \\
15.6 \%\end{array}$ & $\begin{array}{l}23.2 \% \\
33.1 \%\end{array}$ & 12.247 & 0.00 \\
\hline Ease of getting alcohol. & $\begin{array}{l}\text { Hard } \\
\text { Easy }\end{array}$ & $\begin{array}{l}82.9 \% \\
17.1 \%\end{array}$ & $\begin{array}{l}19.4 \% \\
48.6 \%\end{array}$ & 51.925 & 0.00 \\
\hline Would you get caught if you use alcohol without parents' permission? & $\begin{array}{l}\text { Yes } \\
\text { No }\end{array}$ & $\begin{array}{l}72.6 \% \\
27.4 \%\end{array}$ & $\begin{array}{l}22.4 \% \\
29.5 \%\end{array}$ & 5.579 & 0.03 \\
\hline Severe alcohol or drug problem in family? & $\begin{array}{l}\text { No } \\
\text { Yes }\end{array}$ & $\begin{array}{l}75.3 \% \\
24.7 \%\end{array}$ & $\begin{array}{l}21.0 \% \\
33.2 \%\end{array}$ & 18.750 & 0.00 \\
\hline Alcohol use by brothers or sisters. & $\begin{array}{l}\text { No } \\
\text { Yes }\end{array}$ & $\begin{array}{l}71.3 \% \\
28.7 \%\end{array}$ & $\begin{array}{l}20.5 \% \\
33.7 \%\end{array}$ & 23.813 & 0.00 \\
\hline Emotionally close to your mother? & $\begin{array}{l}\text { Yes } \\
\text { No }\end{array}$ & $\begin{array}{l}86.4 \% \\
13.6 \%\end{array}$ & $\begin{array}{l}23.3 \% \\
30.0 \%\end{array}$ & 5.143 & 0.04 \\
\hline Emotionally close to your father? & $\begin{array}{l}\text { Yes } \\
\text { No }\end{array}$ & $\begin{array}{l}85.1 \% \\
14.9 \%\end{array}$ & $\begin{array}{l}22.0 \% \\
31.0 \%\end{array}$ & 4.953 & 0.04 \\
\hline $\begin{array}{l}\text { How wrong do you think it is for people your age to drink alcohol? } \\
\text { Chances you will be seen as cool if used alcohol? }\end{array}$ & $\begin{array}{l}\text { Wrong } \\
\text { Not wrong } \\
\text { None } \\
\text { Some chance }\end{array}$ & $\begin{array}{l}98.5 \% \\
1.5 \% \\
81.9 \% \\
18.1 \%\end{array}$ & $\begin{array}{l}23.5 \% \\
75.9 \% \\
19.1 \% \\
48.7 \%\end{array}$ & $\begin{array}{l}45.172 \\
47.894\end{array}$ & 0.00 \\
\hline Attend religious services & $\begin{array}{l}\text { Sometimes } \\
\text { Never }\end{array}$ & $\begin{array}{l}74.8 \% \\
25.2 \%\end{array}$ & $\begin{array}{l}25.9 \% \\
19.9 \%\end{array}$ & 3.762 & 0.07 \\
\hline Have friends who used or abused alcohol & $\begin{array}{l}\text { Yes } \\
\text { No }\end{array}$ & $\begin{array}{l}25.9 \% \\
74.1 \%\end{array}$ & $\begin{array}{l}50.7 \% \\
15.5 \%\end{array}$ & 160.736 & 0.00 \\
\hline Age group & $\begin{array}{l}11-15 y r s \\
16-20 \text { yrs } \\
21-25 \text { yrs } \\
>25 \text { yrs }\end{array}$ & $\begin{array}{l}19.8 \% \\
66.7 \% \\
11.3 \% \\
2.2 \%\end{array}$ & $\begin{array}{l}11.9 \% \\
31.2 \% \\
36.8 \% \\
93.7 \%\end{array}$ & 28.695 & 0.00 \\
\hline Number of friends who use alcohol & $\begin{array}{l}0 \\
1 \\
2 \\
3 \\
4\end{array}$ & $\begin{array}{l}47.7 \% \\
9.6 \% \\
15.6 \% \\
8.2 \% \\
18.9 \%\end{array}$ & $\begin{array}{l}15.5 \% \\
27.5 \% \\
49.8 \% \\
69.6 \% \\
75.1 \%\end{array}$ & 46.614 & 0.00 \\
\hline
\end{tabular}


services and close to three quarters of the participants did not have friends who used alcohol in the past year (Table I).

We found significant associations between alcohol use and 23 variables (Table I). These were gender, age, cigarette use, stealing, damaging property, carrying weapons, walking home alone at night, bullying or being bullied, thoughts of suicide, knowing adults feel alcohol use was wrong, easily able to obtain alcohol, fear of being caught drinking, having alcohol problems in their families, having siblings who used alcohol, not being close to parents, thinking alcohol use by adolescents was wrong, thinking alcohol use was cool, attending religious services and activities, having friends that used alcohol, and the number of friends who use alcohol.

\section{Logistic regression}

To control for the influence of the multiple explanatory variables on adolescent alcohol use, we then conducted a multiple logistic regression of alcohol use. The model was able to classify $83.5 \%$ of cases correctly. The Nagelkerke R square is 0.409 . In this model, 9 of the 23 explanatory variables entered into the model emerged as best predictors of alcohol use among adolescents. These variables are gender, age, ever having smoked a cigarette, ever damaged property, walking home alone at night, easy availability of alcohol, thinking alcohol use was wrong, attending religious services/activities and number of friends who used alcohol (Table II).

More specifically, gender was a significant partial predictor of alcohol use, with male students having double the odds of ever using alcohol than female students. Being a smoker was strongly associated with ever using alcohol, with smokers having 5.5 times greater odds of using alcohol than non-smokers. In addition, "damaging property" was strongly associated with a greater likelihood of alcohol use. Participants who reported damaging property had 5.5 times greater odds of using alcohol compared to participants who reported never having damaged property. Age was also significantly (albeit weakly) associated with alcohol use, with every one year increase in age increasing the odds of alcohol use by a multiplicative factor of 1.14. Similarly, for every additional friend that used alcohol, the odds of the participant using alcohol increased by a multiplicative factor of 1.4. The odds that students who did not attend religious services used alcohol were 0.32 times that of the students who did attend. In other words, students who did attend religious services had 2.2 times greater odds of using alcohol compared to students who never attended religious services (Table II).

\section{Discussion}

To the best of our knowledge, this study is one of the first to investigate the prevalence and correlates of alcohol use among adolescents in rural high schools in a South African community. In addition, this is the first study of rural adolescents' drinking patterns to use empirically and theoretically derived constructs which have been assessed in relation to adolescent living in the US ${ }^{3}$ and other countries in Sub-Sahara Africa ${ }^{20-23}$ including South Africa ${ }^{5}$ thus enabling us to compare findings across cultures. Our study found that almost a quarter of students report drinking alcohol. Although the prevalence of lifetime alcohol use among high school students in our population is lower than the national average ${ }^{1}$, adolescent drinking in this region is still cause for concern particularly as rates of alcohol use increase as young people get older. Our findings together with evidence from previous studies which points to high rate of alcohol involvement among students from the

\begin{tabular}{|c|c|c|c|c|c|c|c|}
\hline \multirow[t]{3}{*}{ Ever used alcohol? } & \multirow[t]{3}{*}{ Parameter } & \multirow[t]{3}{*}{$B$} & \multirow[t]{3}{*}{ Sig. } & \multirow[t]{3}{*}{ Design Effect } & \multirow[t]{3}{*}{$\operatorname{Exp}(B)$} & $95 \%$ & Confidence \\
\hline & & & & & & \multicolumn{2}{|c|}{ Interval for $\operatorname{Exp}(B)$} \\
\hline & & & & & & Lower & Upper \\
\hline \multirow[t]{10}{*}{ Yes } & Intercept & -4.629 & .000 & 2.259 & .010 & .002 & .045 \\
\hline & Gender=Male & .858 & .000 & 1.269 & 2.360 & 1.566 & 3.556 \\
\hline & Ever smoked a whole cigarette?=Yes & 1.698 & .000 & 1.196 & 5.465 & 3.049 & 9.796 \\
\hline & Damaged property in the past 12 months?=Yes & 1.540 & .001 & 1.568 & 4.665 & 1.967 & 11.061 \\
\hline & Walk home at night in the past 12 months?=Yes & .650 & .013 & 1.605 & 1.916 & 1.165 & 3.149 \\
\hline & Ease of getting alcohol=Easy & .894 & .014 & 2.328 & 2.444 & 1.224 & 4.881 \\
\hline & Do you think alcohol use is wrong?=Not wrong & 1.937 & .059 & 1.328 & 6.935 & .921 & 52.240 \\
\hline & Attend religious services=Never & -.685 & .010 & 1.208 & .504 & .306 & .829 \\
\hline & Age & .133 & .005 & 2.212 & 1.142 & 1.047 & 1.245 \\
\hline & Number of friends who use alcohol & .325 & .000 & .726 & 1.384 & 1.222 & 1.567 \\
\hline
\end{tabular}


University of Limpopo (located in Mankweng) ${ }^{19}$ highlights the need for interventions to prevent alcohol use among high school students in this region.

Nine variables emerged as significant partial predictors of alcohol use among adolescents in Mankweng which resulted in a clear profile to emerge of adolescent who use alcohol in this district. The typical adolescent who drinks in Mankweng is male, older, a smoker, has damaged or destroyed property, walks home alone at night, thinks alcohol is easily available and is easily able to obtain alcohol, does not think there is anything wrong with adolescents who drink alcohol, attends religious and customary activities and has several friends who drink alcohol. With the exceptions of age, gender, ever smoked and easy availability of alcohol, the remaining variables have not been previously reported as correlates of adolescent alcohol use in Mankweng. This profile of the adolescent who is at high risk for the early initiation of alcohol use is important as it may facilitate the early identification of at-risk adolescents by educators and may also aid the development of alcohol prevention and education initiatives targeting high-school students.

In line with previous research in South Africa and in the US, our findings indicate that both personal attributes (such as gender and age), psychological difficulties (indicators of delinquent behaviours) and environment domains (availability and social norms around alcohol use) are correlated with high school students' alcohol use. These findings suggest that in order for adolescent alcohol prevention programmes in this region to be effective, they should address risk factors within both the intrapersonal and environmental domains.

More specifically, gender was significantly correlated with alcohol use, with males more likely to use alcohol than females. This gender difference is in keeping with findings from other studies conducted in the Limpopo region ${ }^{6,12}$, Cape Town ${ }^{16}$, Ghana ${ }^{20}$, Nigeria ${ }^{21-22}$ and Zimbabwe. ${ }^{23}$ These low prevalence rates for young females may be due to the cultural context of the study site which is entirely inhabited by Black African persons for whom traditionally alcohol use and cigarette smoking by adolescents in general and females in particular is culturally prohibited. ${ }^{6}$ According to traditional African values, it would be unmannered, uncultured, and a sign of parental irresponsibility for a typical Black African child to use alcohol or other drugs. ${ }^{9}$ Females that drink alcohol and smoke cigarettes are generally regarded as wayward and some people even associate these behaviours with sex work. It is therefore not surprising that this study found higher levels of alcohol use among males.

While previous studies found indicators of religious affiliation (such as attendance at religious services) to be a protective factor and inversely related to alcohol consumption and/or drug use ${ }^{24-25}$, this was not the case in our study. Studies conducted in other contexts found that involvement in pro-social institutions (such as religious organisations) that have social norms that limit or prohibit alcohol use may protect adolescents against negative peer influences. ${ }^{25}$ This protective effect has been identified at both the individual and group levels. Surprisingly we found the opposite in our study, with participants who never attended religious services significantly less likely to report the use of alcohol than participants who did attend religious services. One possible explanation for this finding may lie in the nature of the survey questions. This study focused on the lifetime use of alcohol and did not explore adolescent drunkenness specifically. The kinds of religion commonly practiced in Mankweng are traditional African religion and the Zionist Christian Church (ZCC). Mankweng is the headquarters of the Zion Christian Church (ZCC) and the majority of families in Mankweng belong to this religious organisation. Alcohol is used in the customary practices and rituals of both of these religious belief systems; therefore it is possible that adolescents were exposed to alcohol use during this context. This however does not mean that these belief systems support or encourage adolescent drunkenness. Another possible explanation may be that large numbers of adolescents may just attend religious activities as part of their family and cultural responsibilities and may not necessarily be particularly committed to a particular belief system or strictly following the prescribed regulations around alcohol use for young people. While further research is needed to unpack the dynamics of the association between religious attendance and alcohol use, it is clear that religious and cultural organisations may be an important place where alcohol-related interventions for at-risk youth can take place in rural settings.

Psychological difficulties as indicated by involvement in delinquent and risky behaviours such as property destruction and walking home alone were also significantly associated with adolescent alcohol use. These findings are in keeping with studies conducted in urban settings which show a strong and consistent relationship between delinquent behaviours and alcohol and drug use among adolescents. ${ }^{4-5,8}$ As almost all of these studies (including the present study) have crosssectional designs, it is difficult to unpack the temporal associations between adolescent alcohol use and delinquent behaviours. Further longitudinal research that tracks adolescents over time is needed to unpack the temporal associations and causal direction of this relationship as it has important implications for the design of interventions to prevent problem behaviours during adolescence. If alcohol use during adolescence precedes indications of delinquent and risky behaviour, then interventions that focus on addressing alcohol use are needed for all adolescents as a means of preventing further risky behaviours. However if the involvement in risky and delinquent behaviour precedes the initiation of alcohol use, then interventions to prevent alcohol use should be targeted specifically at children identified as engaging in high risk and problematic behaviours.

Finally this study also found that environmental factors were significant risks for adolescent alcohol use. Specifically, the perceived availability of alcohol within the community was significantly associated with adolescent drinking, with participants who reported being easily able to obtain alcohol more than twice as likely to drink compared to their peers who could not obtain alcohol easily. In part, this strong association between alcohol availability and adolescent drinking may be a consequence of the high prevalence of home-brewed and informally produced alcohol in Mankweng. ${ }^{14}$ This high prevalence of informally produced alcohol is partly an offshoot of the apartheid era during which time many rural families brewed and sold alcohol from their homes to generate 
income. This practice continues today and alcohol is freely available for adolescents who live in environments where alcohol is produced and sold. ${ }^{14-15}$ This finding suggests that macro-level interventions that control and limit the availability of alcohol (in any form) to adolescents may be a useful structural intervention to delay the early initiation of alcohol use.

\section{Limitations}

One of the limitations of this study is that our measure of alcohol use is a crude one (ever use) as many adolescents will experiment with alcohol and may not necessarily proceed to problematic drinking. Future studies should include measures of problematic drinking during adolescence such as binge drinking, drinking until drunkenness, or other measures of hazardous or harmful use. Another limitation is the exclusion of students that were absent on the day of data collection. It is possible that the students who were absent may have been particularly high-risk and including these students could have produced different prevalence rates. Finally, the findings from this study are specific to Mankweng district and the degree to which these findings can be generalised to other rural communities is unclear. Future studies that explore alcohol use among adolescent in other rural settings are thus needed.

\section{Conclusion}

This study is one of the first in the country to explore correlates of alcohol use among rural adolescents. The study profiled adolescents who were at risk for alcohol use and these students were typically male, older, had many friends who drank, smoked cigarettes, did not think there was anything wrong with drinking, could easily obtain alcohol and had some conduct problems. Adolescents who fit this profile should be carefully monitored by parents, educators and community members and should be the recipients of interventions to prevent alcohol misuse. As the study identified risk factors for alcohol use at multiple levels (including demographic, psychological, interpersonal and environmental domains), our findings suggest that interventions that address personal, family, peer and school conduct risk factors for drinking as part of alcohol prevention initiatives will be more effective than intervention that focus solely on the intrapersonal or environmental level.

\section{Acknowledgements}

The work reported in this paper was supported by fund from the Division of Child and Adolescent Psychiatry, and Adolescent Health Research Institute, University of Cape Town.

\section{References}

1. Reddy SP, James S, Swapaul R, Koopman F, Funani NI, Sifunda S, et al., eds, Umthenthe Uhlaba Usamila - The South African Youth Risk Behaviour Survey 2008. South African Medical Research Council, Cape Town, 2010.

2. Peltzer K, Ramlagan S. Alcohol use trends in South Africa. J Soc Sci, 2009; 18 (1): 1-12.

3. Reddy P, Resnicow $K$, Omardien $R$, et al. Prevalence and correlates of substance use among high school students in South Africa and the United States. Am J Public Health 2007; 10 (97): 1859-1864.

4. Brook JS, Pahl T, Morojele NK, et al. Predictors of drug use among
South African adolescents. J Adolesc Health 2006; 38 (1): 26-34

5. Flisher A J., Parry, C D., Evans J., et al. Substance use by adolescents in Cape Town: prevalence and correlates. J Adolesc Health, 2003; 32:58-65.

6. Madu S N and Ma-Queen P. M. Illicit drug use, cigarette smoking and alcohol drinking behaviour among a sample of high school adolescents in the Pietersburg area of the Northern Province, South Africa, J Adoles 2003; 26 (1): 121-136.

7. Parry CD H, Bhana A, Pluddemann A., et al. Alcohol use in South Africa: Findings from The South African Community Epidemiology Network on Drug Use (SACENDU) Project. J Stud Alcohol 2002; 63:430-435.

8. Morojele NK, Parry CDH, Ziervogel CF, et al.. Adolescent alcohol misuse: Correlates and implications. Afr J Drug \& Alcohol Stud 2000; 1 (2): 110-124.

9. Madu SN, Matla MP. Correlation for perceived family environment factors with substance use among adolescents in South Africa. Psychol Reports 2000; 92: 403-415.

10. Pretorius C, van den Berg, HS, Louw DA Psychosocial predictors of substance abuse among adolescents. Acta Criminologica 2003; 16 (4): $1-11$.

11. Wegner L, Flisher A J, Muller M, et al. Leisure boredom and substance use among high school students in South Africa. J Leisure Research 2006; 389 (2):249-266.

12. Peltzer $K$, Cherian L. Substance abuse among urban and rural secondary school pupils in South Africa. Psychol Reports 2000; 87 (2): 582-584.

13. Peltzer $K$, Cherian VL, Cherian L. Substance use among urban secondary school pupils in the Northern Province, South Africa. S Afr J Child and Adolest Mental Health 1999; 11 (1): 49-55.

14. Onya H, Flisher A. Home brewed alcohol use among high school students in a rural South African community. J Psychol Afr 2006; 1: 65-75.

15. Onya HE, Flisher AJ, Mashambe TJ. Cultural orientation and home brewed alcohol use in a rural community in South Africa. East Afri J Public Health 2009; 6(1):37-42.

16. Statistics South Africa. Statistics in brief. Central Statistics, Pretoria. 2000.

17. Health Systems Trust and the Department of Health, Annual Health Review, Pretoria, 1997.

18. Department of Health: Annual Report. Pretoria. 1997.

19. Peltzer K, Phaswana N. Substance use among South African university students: a quantitative and qualitative study. S Afr Health Info. 1999 .

20. Ado-Mireku, S. The prevalence of alcohol, cigarette, and marijuana use among Ghanaian senior secondary students in an urban setting. J Ethnic in Subst Abuse 2003; 2 (1):53-65.

21. Adelekan ML. Self-reported drug use among secondary school students in the Nigerian State of Ogun. Bull Narcotics 1989; 41: 109116.

22. Nevadomsky J, Self-reported drug use among secondary school students in two-rapidly developing Nigerian towns. Bull Narcotics 1982; 34 (3 \& 4):21-32.

23. Eide, AH and Acuda, SW. Drug use among secondary school students in Zimbabwe. Addiction 1995; 90: 517-27.

24. Miller L, Davies M, Greenwald S. Religiosity and substance use and abuse among adolescents in the National Community Survey. J Am Academy of Child and Adolesc Psychiat 2000; 39: 1190-11 197.

25. Piko BF, Fitzpatrick KM, Substance use, religiosity, and other protective factors among Hungarian adolescents. Addict Behaviour 2004; 29:1095-1107. 